\title{
The role of the lateral amygdala in the retrieval and maintenance of fear-memories formed by repeated probabilistic reinforcement
}

\author{
Jeffrey C. Erlich ${ }^{1 *}$, David E. A. Bush ${ }^{2}$ and Joseph E. LeDoux ${ }^{2}$ \\ 1 Department of Molecular Biology, Broby Lab, Princeton University, Princeton, NJ, USA \\ ${ }^{2}$ Center for Neural Science, New York University, New York, NY, USA
}

Edited by:

Nuno Sousa, University of Minho,

Portugal

Reviewed by:

José M. Pêgo, University of Minho, Portugal

Kerry J. Ressler, Emory University, USA

*Correspondence:

Jeffrey C. Erlich, Department of

Molecular Biology, Princeton

University, Princeton, NJ 08544,

USA.

e-mail: jerlich@princeton.edu
The lateral nucleus of the amygdala (LA) is a key element in the neural circuit subserving Pavlovian fear-conditioning, an animal model of fear and anxiety. Most studies have focused on the role of the LA in fear acquisition and extinction, i.e., how neural plasticity results from changing contingencies between a neutral conditioned stimulus (CS) (e.g., a tone) and an aversive unconditioned stimulus (US) (e.g., a shock). However, outside of the lab, fear-memories are often the result of repeated and unpredictable experiences. Examples include domestic violence, child abuse or combat. To better understand the role of the LA in the expression of fear resulting from repeated and uncertain reinforcement, rats experienced a $30 \%$ partial reinforcement (PR) fear-conditioning schedule four days a week for four weeks. Rats reached asymptotic levels of conditioned-fear expression after the first week. We then manipulated LA activity with drug (or vehicle) (VEH) infusions once a week, for the next three weeks, before the training session. LA infusions of muscimol (MUSC), a GABA-A agonist that inhibits neural activity, reduced CS evoked fear-behavior to pre-conditioning levels. LA infusions of pentagastrin (PENT), a cholecystokinin-2 (CCK) agonist that increases neural excitability, resulted in CS-evoked fear-behavior that continued past the offset of the CS. This suggests that neural activity in the $L A$ is required for the retrieval of fear memories that stem from repeated and uncertain reinforcement, and that CCK signaling in the LA plays a role in the recovery from fear after the removal of the fear-evoking stimulus.

Keywords: amygdala, fear, rats, recovery, muscimol, cholecystokinin, partial reinforcement

\section{INTRODUCTION}

The lateral nucleus of the amygdala (LA) is a key component of the neural circuitry sub-serving Pavlovian fear-conditioning (Maren and Quirk, 2004). Fear-conditioning is a behavioral procedure involving the pairing of a neutral conditioned stimulus (CS) with an aversive unconditioned stimulus (US). Following CS-US pairing, the CS comes to elicit defensive fear-behaviors (Blanchard et al., 1993). Much progress has been made in understanding the role of the amygdala in learning and consolidation of the CS-US association (Lamprecht and LeDoux, 2004; Rodrigues et al., 2004; Schafe et al., 2005; Pape and Pare, 2010; Johansen et al., 2011). These studies generally use continuous reinforcement, where every presentation of the CS in acquisition is followed by the presentation of a US. However, it is also important to understand the mechanisms for the retrieval of fearmemories that are the result of partial reinforcement (PR), where the CS probabilistically predicts the US. This is especially true in a clinical context-abused children and soldiers can suffer from post-traumatic stress disorder (PTSD) that stems from repeated probabilistic associations (Foa and Meadows, 1997).

The physiological and behavioral consequences of partial reinforcement in fear-conditioning depend on a variety of factors. Probabilistic CS-US associations can be more stressful than predictable CS-US associations (McGuire et al., 2010). The uncertainty of the outcome (for example, waiting for the results of a biopsy with a $30 \%$ chance of being positive) can result in high levels of anxiety (Poole et al., 1999; Thompson and Hepburn, 2003), which may involve distinct neural mechanisms than those involved in certain CS-US associations (Yu and Dayan, 2005). Partial reinforcement can also result in learning that is resistant to extinction, a phenomena known as the "partial reinforcement extinction effect" (Wagner et al., 1967). Negative mood, depression, or stress can bias subjects to interpret ambiguous cues as more aversive (Msetfi et al., 2005; Tsetsenis et al., 2007). Human studies of fear-conditioning commonly use partial reinforcement and have demonstrated that the amygdala activity correlates with behavioral measures of fear during this paradigm (LaBar et al., 1998; Delgado et al., 2008; Dunsmoor et al., 2008), which suggests that the amygdala plays a similar role in learning and retrieval of partially reinforced CS-US associations as it does in continuously reinforced CS-US associations. Despite extensive behavioral and neuroimaging studies investigating the effects of partial reinforcement in fear-conditioning, there are relatively few studies of the neural bases of these phenomena in animals. This is somewhat surprising given that fear-conditioning has been a tremendously successful translational tool for treating 
human fear disorders (Ressler et al., 2004; Phelps et al., 2004; Davis et al., 2006; Bush et al., 2007; Quirk et al., 2007; Dębiec et al., 2011), which likely depend more on probabilistic than continuous reinforcement.

Here we investigated the relationship between neural activity in the LA and fear-expression evoked by repeated exposure to a CS partially reinforced with footshock. We designed a lick suppression task suited to examining within-subject pharmacological manipulations that could result in either increased or decreased fear-expression and also the expression of fear both during and after the CS.

We chose to use two drugs to bidirectionally modulate LA activity in this task: muscimol (MUSC), a GABA-A agonist, and pentagastrin (PENT), a CCK2 agonist. We hypothesized that MUSC would reduce conditioned fear-expression and PENT would increase conditioned fear-expression. Muscimol functionally inactivates neurons by binding to and activating GABA-A receptors. Previous studies have demonstrated that muscimol inactivation of the LA blocks the expression of fear in typical fear conditioning experiments where training consists of a few reliable CS-US pairings, and testing is done within $24 \mathrm{~h}$ of training (Wilensky et al., 2000; Maren, 2001; Blair et al., 2005).

Pentagastrin is an agonist of the cholecystokinin-2 $\left(\mathrm{CCK}_{2}\right)$ receptor, a G-protein coupled receptor which has been shown to cause an increase in the excitability of neurons in the basolateral amygdala via activation of a non-specific cation channel (Meis et al., 2007; Chung and Moore, 2009). Pentagastrin injected intravenously causes panic attacks (Bradwejn et al., 1990; Geraci et al., 2002), which has generated interest in the role of CCK in anxiety. In fear-potentiated startle, intra-amygdala blockade of $\mathrm{CCK}_{2}$ receptors blocks the anxiogenic effect of systemic PENT (Frankland et al., 1997), suggesting that $\mathrm{CCK}_{2}$ binding in the amygdala may be responsible for the panic inducing effects of CCK in humans. Aside from the pre-clinical interest in the contribution of the CCK system to the retrieval of chronic probabilistic fear-memory, we used PENT in this study because local infusion of the drug into the LA of rats potentiated acoustic startle without affecting baseline activity (Frankland et al., 1997). By definition, it is necessary to measure lick suppression against a baseline level of licking activity, so we avoided drugs that have strong effects on baseline behavior, including GABA-A antagonists like picrotoxin and bicuculline, which are known to have general anxiogenic and epileptogenic effects (Gean and Shinnick-Gallagher, 1987; Sanders and Shekhar, 1995; Chu and Lin, 1996).

\section{MATERIALS AND METHODS}

Subjects. Subjects were adult male Sprague Dawley rats (Hilltop, PA) weighing 350-400 g. They were housed individually in plastic Nalgene cages and maintained on a $12 \mathrm{~h}$ light/dark cycle. Water was provided freely throughout the experiment. After recovery from surgery (see below) they were maintained on a restricted diet until they reached $90 \%$ of their original body weight. All procedures were in accordance with Public Health Service guidelines and were approved by the animal use committee of New York University. Ten rats underwent surgery. Two animals never met criteria for pre-habituation (described below) and one animal was excluded due to an erroneous cannula placement.
Surgery. Under ketamine (100 mg/kg, i.p.), xylazine $(6.0 \mathrm{mg} / \mathrm{kg}$, i.p.), and medetomidine $(0.5 \mathrm{mg} / \mathrm{kg}$, i.p.) anesthesia, rats were implanted bilaterally with 22-gauge stainless steel guide cannulae that terminated $1.5 \mathrm{~mm}$ above the target location in the LA. The target location coordinates, taken from Paxinos and Watson (2004), were +5.7 anteroposterior, \pm 5.3 mediolateral, and $+2.0 \mathrm{~mm}$ dorsoventral with reference to inter-aural zero. The guide cannulae were anchored to the skull with dental cement. A 28-gauge dummy cannula was inserted into each guide cannula to prevent clogging, and dummy cannulae were changed once per week. After surgery, rats were given buprenorphine $\mathrm{HCl}$ $(0.2 \mathrm{mg} / \mathrm{kg}$, s.c. $)$ as an analgesic. Rats were given at least $5 \mathrm{~d}$ to recover from surgery before the beginning of behavioral training.

Drugs. The vehicle (VEH) was 50 millimolar sodium bicarbonate in physiological saline $(0.9 \% \mathrm{NaCl})$. The PENT infusion was $0.375 \mu \mathrm{g}$ of pentagastrin (B1636, Sigma-Aldrich) in $0.25 \mu \mathrm{L}$ of VEH (Frankland et al., 1997). The MUSC infusion was $0.125 \mu \mathrm{g}$ of muscimol (M1523, Sigma-Aldrich) in $0.25 \mu \mathrm{L}$ of physiological saline (Wilensky et al., 2000).

Behavior. All behavior took place in a Plexiglas chamber with dimensions $23 \mathrm{~cm} \times 28 \mathrm{~cm} \times 34 \mathrm{~cm}$ (Med-Associates, Inc.) with a recessed lick spout enclosed in a sound and light attenuating chamber during the rat's light cycle. The CS was an auditory stimulus made up of 20 pure tone pips. The frequency of each pip was $12 \mathrm{kHz}$ and duration was $250 \mathrm{~ms}$. The interval between pip onsets was $1 \mathrm{~s}$. Thus, the total duration of the CS was $20 \mathrm{~s}$. The US was a brief footshock $(0.5 \mathrm{~mA}, 200 \mathrm{~ms})$ delivered $20 \mathrm{~s}$ after the onset of the CS. Conditioned lick suppression was used as our measure of fear and was quantified as a suppression ratio (Repa et al., 2001). The suppression ratio was defined as $\left(L_{P R E}-L_{C S}\right) /\left(L_{P R E}+L_{C S}\right)$ where $L_{P R E}$ is the number of licks in the $20 \mathrm{~s}$ pre-CS period and $L_{C S}$ is the number of licks in the $20 \mathrm{~s}$ CS period. Trials with no CSevoked suppression have a suppression ratio of zero. CS-evoked suppression results in positive suppression ratios. Complete suppression (no licking during the CS) results in a suppression ratio of one. CS-evoked facilitation of licking results in negative suppression ratios.

After recovery from surgery rats were pre-habituated to the behavioral chamber where they were trained to lick for a sugary orange drink (Kool-Aid ${ }^{\circledR}$, Kraft Foods; $5 \mathrm{~g} / 100 \mathrm{~mL}$ water) to maintain a constant level of activity against which suppression could be reliably measured. This phase of training lasted 3-6 days. By giving the rats extensive exposure to the context before conditioning, we tried to minimize any contextual fear-conditioning (Escobar et al., 2002). Once the rats licked consistently, the behavioral training began (Figure 1). The experiment lasted five weeks. The first week consisted of one habituation (HAB) session and an initial training session the following day. For the habituation session (HAB), rats were placed in the chamber for a 20 trial session with an inter-trial interval of 1-4 min. Each trial was a presentation of the CS. The next day rats returned to the chamber for a 20 trial session with a 30\% CS-US contingency. This session resulted in the initial formation of the CS-US association.

In the following weeks, each animal had one partial reinforcement (PR) session per day for four days (Monday-Thursday). 


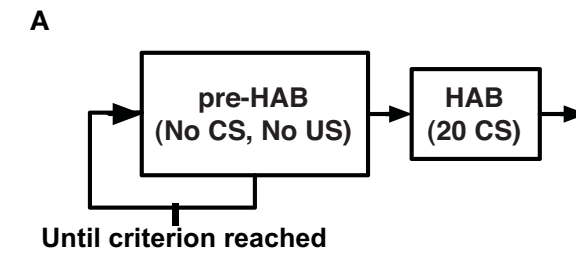

B

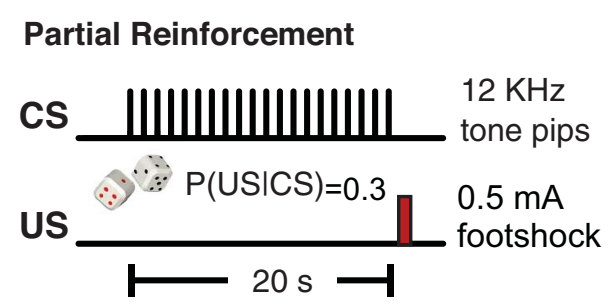

FIGURE 1 | Partial-reinforcement auditory fear-conditioning paradigm (A) Animals were pre-habituated (pre-HAB) to the behavioral apparatus and to the orange drink. This continued until they reach a criterion of licking consistently for $1 \mathrm{~h}$. Habituation $(\mathrm{HAB})$ consisted of 20 presentations of the $\mathrm{CS}$ with no reinforcement. The next day partial reinforcement (PR) fear-conditioning began. Each training session consisted of 20 presentation of the CS with a $30 \%$ probability of the CS being followed by the US.

The first week (PR0) was four conditioning sessions with no infusions. On the following weeks (PR1-3) the first three days were conditioning days with no infusions and on the fourth day (of weeks PR1-3) each animal received a bilateral intraLA infusion of either VEH, PENT, or MUSC, counterbalanced across weeks $15 \mathrm{~min}$ before the conditioning session. Specifically, three rats received PENT, then MUSC, then $\mathrm{VEH}$, two rats received $\mathrm{VEH}$, then PENT, then MUSC and two rats received MUSC, then VEH, then PENT infusions in weeks PR1, PR2, and PR3, respectively. As such, over the course of the experiment each rat received all three infusions. Since the behavior preceding each infusion day was not statistically different, we present the effects of drug and $\mathrm{VEH}$ on suppression ratio without adjusting for the activity during the preceding days. The CS-US contingency was the same (30\%) for infusion and non-infusion days.

Intracranial infusions. Rats were held in the experimenter's lap while dummy cannulae were replaced with 28 gauge infusion cannulae attached to $1.0 \mu$ l Hamilton (Reno, NV) syringes via polyethylene tubing. The infusion cannula extended $1.5 \mathrm{~mm}$ beyond the tip of the guide cannula directly into the target location in the LA. The tubing was back-filled with sesame oil, with a small air bubble separating the oil from the drug. Drugs were infused bilaterally using an infusion pump, and cannulae were left in place for an additional 2 min after infusion to allow diffusion of the drug away from the cannula tip before dummy cannula replacement. A total amount of $0.25 \mu \mathrm{l}$ of drug or VEH was infused into the LA bilaterally over $105 \mathrm{~s}$. This volume was chosen on the basis of autoradiographic studies of the spread of MUSC applied to the size and structure of the target

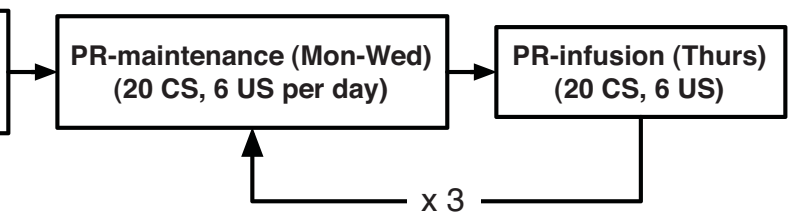

C

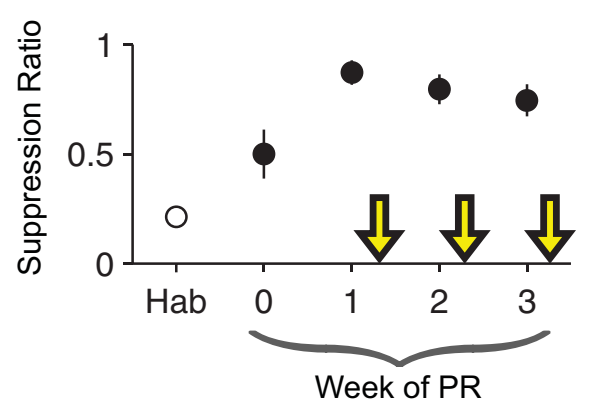

The first infusion was given after six days of PR. (B) The CS was series of twenty $250 \mathrm{~ms}, 12 \mathrm{kHz}$ pure tone pips presented once per second for 20 s. On $30 \%$ of trials a $200 \mathrm{~ms}$ footshock US $(0.5 \mathrm{~mA})$ was given $20 \mathrm{~s}$ after the start of the CS $(750 \mathrm{~ms}$ after the end of the last $12 \mathrm{KHz}$ pip). (C) Suppression ratio on non-drug training days stabilized after an initial three days of training. Yellow arrows indicate infusion days.

(Martin, 1991). Infusions preceded the behavioral session by $15 \mathrm{~min}$. The effects of MUSC have been shown to last for hours (Edeline et al., 2002). We are unaware of studies that have directly examined the duration of the effects of PENT, however, other studies that have used PENT also waited 15-20 min after infusion before measuring significant behavior effects (Singh et al., 1991; Frankland et al., 1997; Chhatwal et al., 2009).

Data analysis. All statistical analyzes were performed using Statistica 7.0 (Statsoft; Tulsa, OK) or MATLAB (versions 6.5 or later) (Mathworks; Natick, MA). For all analyzes, trials were excluded if the rat did not lick during the pre-CS period for that trial. For the ANOVA, trials for each rat were averaged and effects were tested using a repeated measures design with each rat as a case and the drug as the factor. For post-hoc tests comparing specific groups we used multcompare (MATLAB) using Tukey's honestly significantly different test (HSD). For testing the correlations between cannula placement and drug effects we used corrcoef MATLAB.

Histology. To verify infusion cannula tip locations, rats were anesthetized with an overdose of chloral hydrate $(600 \mathrm{mg} / \mathrm{kg}$, i.p.) and perfused transcardially with $10 \%$ buffered formalin. The brains were post-fixed in $30 \%$ sucrose in formalin and subsequently blocked, sectioned on a cryostat at $50 \mu \mathrm{m}$, and stained for Nissl using $0.5 \%$ cresyl violet. Sections were coverslipped with Permount (Fisher Scientific) and examined under light microscopy for tip penetration into the amygdala (Figure 5). The mean placement in $\mathrm{mm}$ with respect to inter-aural zero was (mean \pm standard error): AP, $-5.59 \pm 0.04 ; \mathrm{ML}, 5.19 \pm 0.09 ; \mathrm{DV}$, $2.17 \pm 0.10$ (Paxinos and Watson, 2004). 


\section{RESULTS}

We trained male Sprague Dawley (Hilltop, PA) rats on a probabilistic fear-conditioning paradigm: a 30\% CS-US contingency, against a background of appetitive motivation-access to a sweet orange KoolAid ${ }^{\odot}$ drink. This allowed us to measure both the degree of lick suppression during the CS and also the time to resume drinking after the CS. We chose $30 \%$ because a pilot experiment of different contingencies (data not shown) demonstrated that low CS-US contingencies $(\leq 10 \%)$ resulted in CS-evoked suppression that was too low and high CS-US contingencies $(100 \%)$ resulted in CS-evoked suppression that was too high to be able to observe both increases and decreases in lick suppression in response to manipulations of neural activity. We measured lick suppression instead of freezing because the background of appetitive motivation enabled us to measure recovery from fear, which may be an important factor for psychological resilience (Charney, 2004; Yehuda et al., 2006; Bush et al., 2007).

After recuperating from bilateral implantation of cannulae into the LA $(5.7 \mathrm{~mm}$ anterior, $\pm 5.3 \mathrm{~mm}$ lateral and $2 \mathrm{~mm}$ dorsal to inter-aural zero), rats were pre-habituated to the conditioning chamber and to the orange-flavored drink: they were simply placed in the chamber and left there for $1 \mathrm{~h}$ per day until they drank consistently over that period (Figure 1A). Then, there was a single habituation (HAB) session (20 presentations of the CS) followed by four days a week of partially reinforced conditioning (PR) for four weeks. As with the HAB phase, during PR there were 20 presentations of the CS, but during PR there was a $30 \%$ chance that the CS would be followed by a US $(0.5 \mathrm{~mA}$, $200 \mathrm{~ms}$ footshock). The first week was initial training with no infusions. Starting in the second week, the first three days of conditioning each week were no-infusion sessions, and on the fourth day rats were infused with VEH, MUSC or PENT. Rats received each infusion over the course of three weeks in a different order. Conditioned lick suppression was detectable after the first CS-US pairing and the suppression ratio during no-infusion days was significantly greater than during HAB (Figure 1C, paired $t$-test, $\left.t_{6}=6.67, p<0.001\right)$. The suppression ratio was defined as $\left(L_{P R E}-L_{C S}\right) /\left(L_{P R E}+L_{C S}\right)$ where $L_{P R E}$ is the number of licks in the $20 \mathrm{~s}$ pre-CS period and $L_{C S}$ is the number of licks in the $20 \mathrm{~s}$ CS period. The CS-evoked suppression was not different during the no-infusion days preceding VEH, MUSC or PENT infusion days (ANOVA, $p=0.957$ ). The order of infusion (VEH, MUSC, PENT) was counter-balanced across animals.

The pharmacological manipulations in the LA had a significant effect on suppression ratio $\left[F_{(3,18)}=7.03, p<0.005\right.$; Figure 2A]. Suppression ratio during MUSC sessions was significantly reduced relative to both $\mathrm{VEH}$ and PENT sessions $(p<$ 0.05; Tukey's HSD). Additionally, MUSC appeared to completely abolish the effect of fear-conditioning, since there was no significant difference in the suppression ratio between the HAB and MUSC sessions ( $p>0.5$, Tukey's HSD). We did not find a significant difference in suppression ratio between VEH and PENT sessions ( $p>0.5$; Tukey's HSD).

Since the suppression ratio is a function of CS and pre-CS licking, it is possible that the effect of MUSC on lick suppression was due to changes in pre-CS licking. However, an analysis of pre-CS licking in the four conditions shows no difference in the amount of pre-CS licking between HAB, VEH, MUSC, and PENT sessions $\left[F_{(3,18)}=1.58, p>0.2\right.$; Figure $\left.2 \mathbf{B}\right]$, indicating that the drug effect on suppression ratio is attributable to a change in licking during the CS.

It is possible (though unlikely) that MUSC infusions into the LA attenuated lick suppression during the CS because of a sensory or motor deficit that impaired infused rats from processing sensory input or suppressing licking. To verify that the effect of MUSC was specific to the CS-evoked suppression we examined whether the drug also prevented US-evoked suppression. To quantify this we compared the latency to resume licking after CS-US versus CS-alone trials. Figure 2C illustrates that MUSC decreases the latency to resume licking after a CS $\left[F_{(2,10)}=\right.$ $21.3, p<0.0005]$ but not a US $\left[F_{(2,10)}=0.24, p>0.79\right]$ compared to VEH and PENT (Figure 2C). This effect was robust: all
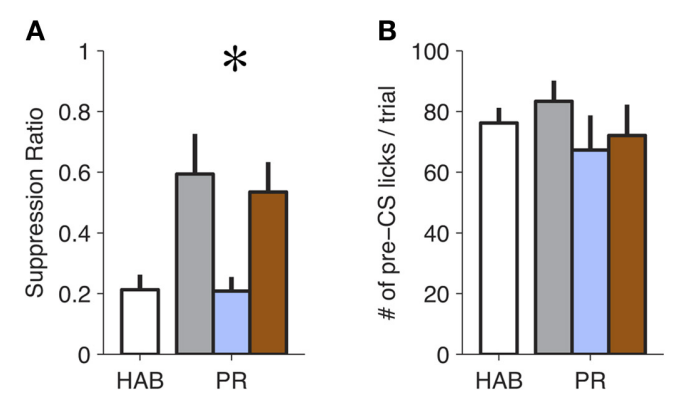

FIGURE 2 | Muscimol reduces expression of conditioned fear to pre-conditioning levels. (A) Mean \pm SE CS-evoked suppression ratio from habituation (HAB), vehicle (VEH), muscimol (MUSC), and pentagastrin (PENT) sessions. Muscimol significantly reduced levels of suppression compared to vehicle and pentagastrin [Repeated Measures ANOVA, $F_{(3,18)}=7.03$, $p<0.005$ ]. (B) Mean \pm SE number of licks during the 20 s pre-CS interval from HAB, VEH, MUSC and PENT sessions. ( $n=7)$. Drug-treatment did not affect pre-CS lick levels [Repeated Measures ANOVA, $F_{(3,18)}=1.58$, $p>0.2$ ]. (C) Mean \pm SE latency to lick (seconds) after a CS-alone

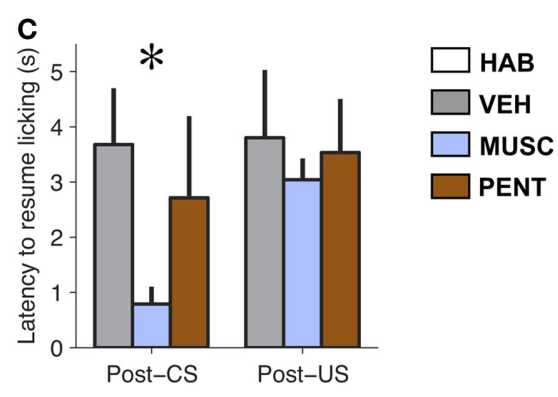

trial (CS) or a CS-US trial (CSUS) ( $n=7)$. Muscimol reduces post-CS suppression but does not eliminate post-US suppression. The VEH was 50 millimolar sodium bicarbonate in $0.25 \mu \mathrm{L}$ of physiological saline $(0.9 \% \mathrm{NaCl})$. The PENT infusion was $0.375 \mu \mathrm{g}$ of pentagastrin (B1636, Sigma-Aldrich) in $0.25 \mu \mathrm{L}$ of vehicle. The MUSC infusion was $0.125 \mu \mathrm{g}$ of muscimol (M1523, Sigma-Aldrich) in $0.25 \mu \mathrm{L}$ of physiological saline. A total amount of $0.25 \mu \mathrm{l}$ of drug or vehicle was infused into the LA bilaterally over $105 \mathrm{~s}$. Infusions preceded the behavioral session by $15 \mathrm{~m}$. 

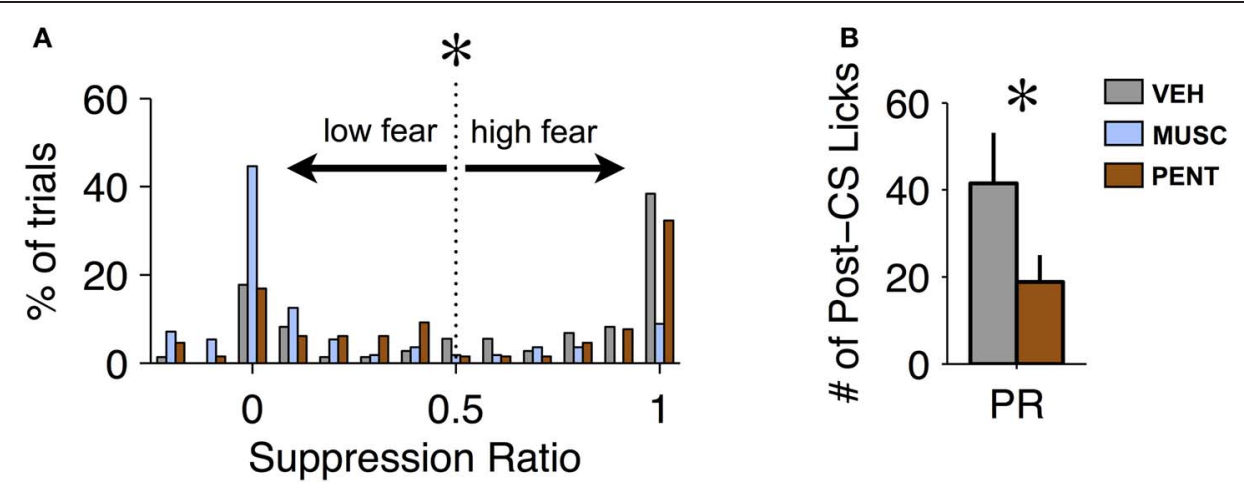

FIGURE 3 | Pentagastrin impairs recovery from fear. (A) Histogram of suppression ratio across trials for vehicle (gray), muscimol (blue), and pentagastrin (brown) sessions. The suppression ratio distribution is significantly bimodal for vehicle and pentagastrin (Hartigan's Dip Test, $p<0.001$ for both vehicle and pentagastrin) but not for muscimol (Dip Test, $p>0.7)$. In order to test recovery from fear we consider only the "high fear" trials: trials where the suppression ratio was greater than 0.5. (B) Mean $\pm \mathrm{SE}$ number of licks during the $20 \mathrm{~s}$ post-CS interval from vehicle and pentagastrin sessions after CS-alone trials where the suppression ratio was greater than 0.5. Post-CS licking after "high fear" trials, a proxy to recovery from fear, was significantly lower in pentagastrin sessions than vehicle sessions [ANOVA, $\left.F_{(1,6)}=8.05, p=0.006\right]$. rats in MUSC sessions took longer to resume licking on average after a CS-US trial than a CS trial. Moreover, if the MUSC caused an auditory impairment such that the rats could not hear the CS, we would expect that the mean suppression should be zero. The suppression during the MUSC session was significantly greater than zero $\left(t\right.$-test, $\left.t_{6}=4.51, p<0.005\right)$.

While changes in suppression during the CS are one way to detect an effect of a drug, the recovery from fear after the offset of the CS could also provide important behavioral information. Our proxy for recovery was the number of licks in the $20 \mathrm{~s}$ post-CS period (excluding CS-US trials). Recovery from fear can only be measured on trials where fear was expressed. We observed that the suppression ratio across trials was bimodal for VEH and PENT sessions (Hartigan's Dip Test, $p<0.001$ for both VEH and PENT, Figure 3A). This indicates that, in these sessions, the conditioned response on any given trial tended toward all or none: either the animal "ignored" the CS on that trial or they suppressed licking during most of the CS. This was not the case for MUSC sessions (Dip Test, $p>0.7$, Figure 3A) where the mode of the distribution of the suppression ratio was at 0 , indicating that the CS was "ignored" on most trials. For our analysis we considered a trial to be "high fear" (and valid for measuring recovery) if the suppression ratio was greater than 0.5 (Figure 3A), meaning there was a $66 \%$ reduction in licking from the pre-CS period to the CS period. To quantify the recovery from fear we analyzed the number of post-CS licks for trials where the CS elicited suppression according to the "high fear" criteria. We found that PENT infusions resulted in significantly increased maintenance of suppression beyond the termination of the CS compared with VEH [ANOVA, $\left.F_{(1,6)}=8.05, p<0.007\right]$. This suggests that activation of the CCK system in the LA results in fear-expression that persists past the offset of the CS. Since MUSC reduced CS-evoked suppression to pre-conditioning levels there were not enough "high fear" trials to include these sessions in the statistical analysis.

Although the focus of these experiments was not to study reconsolidation (Nader et al., 2000) of conditioned fear, we examined the expression of fear on the first no-infusion day

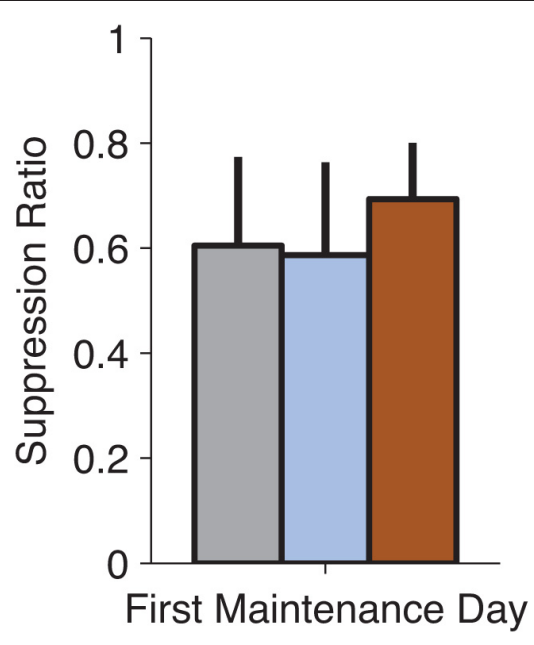

FIGURE 4 | No observable effects on fear-expression on the no-infusion day following drug treatment. We examined whether our pharmacological manipulations of the LA (on Thursdays) affected the following day of training (on Monday). Suppression Ratio on the first day following each manipulation was not significantly different (ANOVA, $p>0.8$ ) suggesting that the drug treatments did not affect the reconsolidation of the fear-memory.

following an infusion to test whether our manipulations might have disrupted reconsolidation. This was especially relevant for MUSC, where the manipulation reduced fear-expression to preconditioning levels (Figure 2A). We did not find any reconsolidation effect of drug infusion when tested on the following day of training (Figure 4, ANOVA, $p>0.8$ ). This is consistent with the idea that MUSC in the LA blocks the retrieval of the fearmemory that would be required to make it labile and susceptible to disruption.

\section{DISCUSSION}

We modified the standard fear-conditioning paradigm to examine the role of the LA in the retrieval of a probabilistic CS-US 
association that evoked conditioned suppression which was stable across multiple days (Figure 1C). We demonstrated that inactivation of the LA with MUSC before a training session disrupts CS-evoked suppression in that session even though the subject has experienced weeks of repeated exposure to the CS and US. We also demonstrated that PENT infusions into the LA resulted in enhanced maintenance of CS-evoked lick suppression beyond the offset of CS. This supports existing evidence that LA neuronal activity is required for the retrieval of probabilistic CS-US associations, and provides new evidence that LA $\mathrm{CCK}_{2}$ receptor activation impairs the short-term recovery from conditioned fear.

We initially predicted that MUSC and PENT would have opposite effects on conditioned fear expression: that MUSC would attenuate lick suppression and PENT would enhance it. As predicted, MUSC attenuated lick suppression, consistent with many previous studies that have demonstrated that MUSC inactivation of the LA blocks the expression of fear (Wilensky et al., 2000; Maren, 2001; Blair et al., 2005). The novelty of our finding is that MUSC blocked fear-expression evoked by a partially reinforced CS that was experienced repeatedly for several weeks. The previous studies only examined the effects of MUSC on a recently learned 100\% contingent CS-US association.

Pentagastrin did not increase lick suppression during the CS. This lack of effect is unlikely to be a type II error (false negative) because the mean suppression ratio in PENT sessions was actually lower than $\mathrm{VEH}$, indicating that it was not a lack of statistical power which resulted in this effect not reaching significance. It may be possible to observe PENT-enhanced lick suppression during the CS in a weaker conditioning paradigm: for example, a conditioning paradigm that resulted in lower asymptotic level of suppression (Figure 1C) either through a lower shock intensity or lower CS-US contingency. Still, PENT had a significant effect on behavior. It resulted in prolonged maintenance of lick suppression beyond the offset of the CS. This suggests that increasing excitability of neurons in the LA attenuates an animal's ability to recover from fear.

CCK is produced by several distinct inter-neuronal populations in the basal and lateral nuclei of the amygdala (BLA) with broad axonal arbors that terminate locally in the BLA but also project medially and laterally, possibly to the central nuclei or intercalated cell-masses of the amygdala (Jasnow et al., 2009). In the rat, $\mathrm{CCK}_{2}$ receptor activation depolarizes inhibitory interneurons (Chung and Moore, 2009). At first glance this seems contradictory to our finding and to the general result that $\mathrm{CCK}_{2}$ receptor agonism is anxiogenic (Singh et al., 1991; Frankland et al., 1997; Rotzinger and Vaccarino, 2003). However, information flow from the LA to the central amygdala outputs that control conditioned suppression (Amorapanth et al., 1999; Ehrlich et al., 2009), is controlled by an intricate circuit of excitatory and inhibitory neurons in the basal, central and intercalated amygdala nuclei. It may be that amygdalar excitatory $\mathrm{CCK}_{2}$ expressing interneurons inhibit the inhibitory neurons that project to the central nucleus to inhibit fear-expression. Thus excitation of these neurons may result in disinhibition of central nucleus projection neurons that drive conditioned suppression (See Figure 3 of Ehrlich et al., 2009). This circuit has been proposed as a potential mechanism by which extinction learning inhibits fear-expression. It has recently been shown that $\mathrm{CCK}_{2}$ receptor activation can impair the extinction of fear-potentiated startle (Chhatwal et al., 2009) suggesting that a common circuit, subject to modulation by CCK, plays a role in the short-term recovery from fear and also extinction learning.

\section{SPREAD OF DRUGS}

One concern with drug infusion studies is that drugs could spread outside the target area. In this study, the target was the LA, but the drug effects could have been due to receptor stimulation in adjacent structures like the basal or central nuclei of the amygdala. However, several lines of evidence suggest that the behavioral effects observed were due to modulation of LA activity, and not an adjacent area. First, the histological placement of the injection sites (Figure 5) did not correlate with suppression ratio (tested Pearson correlation of right and left AP, ML, and DV versus the suppression ratio during MUSC sessions, all $p$ 's $>0.2$ ). If the drug effects were due to spread to the basal nucleus we would expect more ventral injection sites to have a stronger effect. If the drug effects were due to spread to the central nucleus we would expect more medial sites to have a stronger effect. Second, a previous study that injected CCK-8 (an endogenous ligand of both CCK-1 and CCK-2 receptors) into the central nucleus of the amygdala found that it produced generalized anxiety behavior (Belcheva et al., 1994). In contrast, we observed no effect of PENT infusions on pre-CS licking, only on CS-evoked suppression. This is more consistent with the role of the LA than the role of the central nucleus on expression of fear (Pare et al., 2004). Finally, a study that used a similar volume of MUSC $(0.2 \mu \mathrm{L})$ to examine the roles of the LA and the central nucleus of the amygdala in fear-conditioning conducted extensive controls to demonstrate that there was no detectable spread of drug between the LA and the central nucleus at that volume (for details see Wilensky et al., 2006).

\section{MEMORY RETRIEVAL VERSUS EXPRESSION OF BEHAVIOR?}

The effect of MUSC infusions in the LA on lick suppression could be interpreted in two ways. One interpretation is that activity in the LA is required for the expression of lick suppression. The second interpretation is that activity in the LA is required for retrieval of the CS-US association. Although we cannot fully justify one interpretation over the other, we tend to favor the second interpretation for the following reasons. Inactivation of the LA with MUSC did not abolish lick suppression in response to the footshock US (Figure 2C). This alone is not conclusive since footshock is more intense than the CS. Thus, the difference between suppression to the CS and the suppression to the US may be a quantitative but not a qualitative difference. A second piece of evidence is that MUSC inactivation of LA blocked the expression of conditioned fear during the infusion session (Figure 2A), but had no effect on the expression of conditioned fear in the following training session (Figure 4). If the conditioned fear had been retrieved but the expression of fear blocked, then the attenuation of expression should have disrupted the reconsolidation of the memory. This phenomena has been observed with the $\beta$ adrenergic antagonist propranolol (Dębiec et al., 2011). As well, 

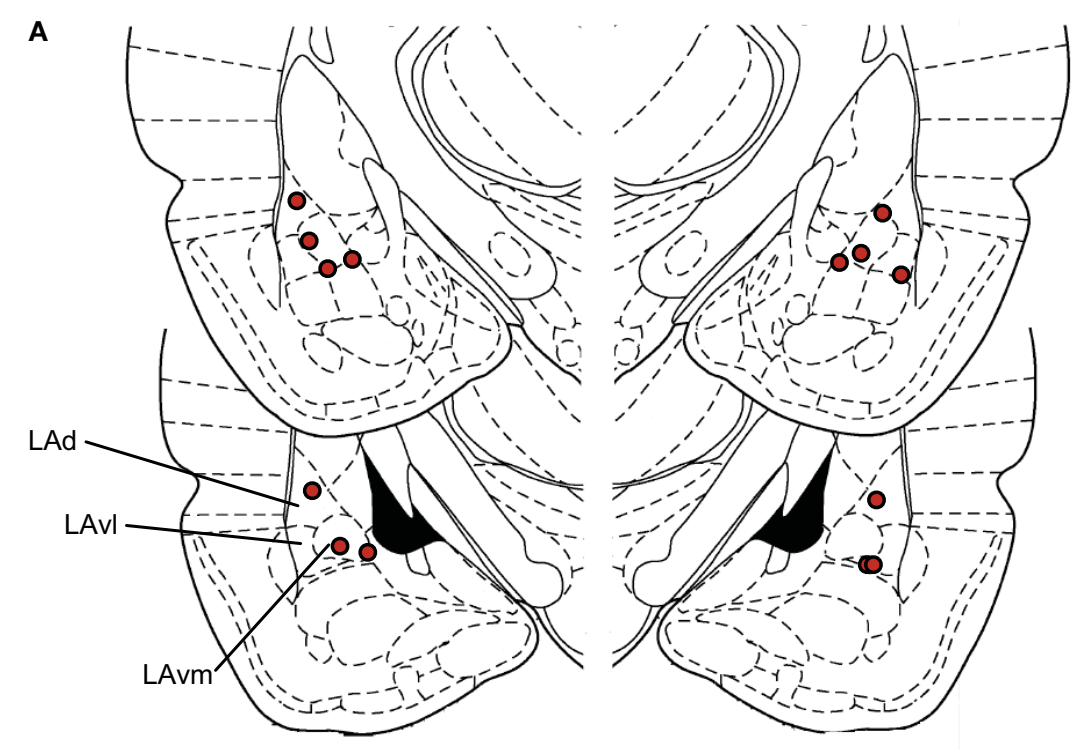

\section{7}

B

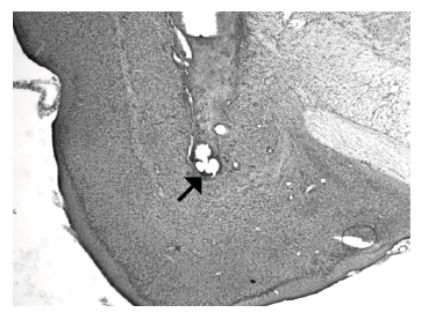

FIGURE 5 | Histological verification of cannula placements in the LA. (A) Rats were implanted bilaterally with 22-gauge stainless steel guide cannulae that terminated $1.5 \mathrm{~mm}$ above the target location in the LA. The target location coordinates, taken from Paxinos and Watson (2004), were +5.7 anteroposterior, \pm 5.3 mediolateral, and $+2.0 \mathrm{~mm}$ dorsoventral with reference to inter-aural zero. Locations of cannula tip

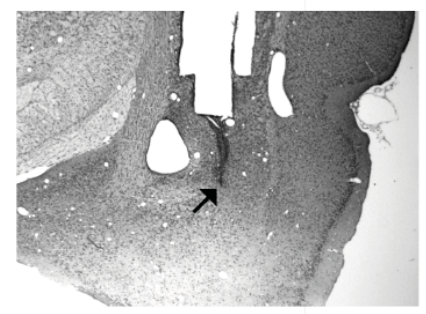

\section{4}

placements where infusions were delivered are indicated with diamonds. Numbers indicate anterior-posterior distance $(\mathrm{mm})$ from inter-aural zero. (Dorsal LA - LAd; ventrolateral LA - LAvl; ventromedial LA - Lavm). (B) Examples of Nissl stained sections used to construct A. Modified from Paxinos and Watson (2004), with permission from Elsevier $^{\complement} 2004$. several lines of evidence from the literature indicate that activity in the LA encodes the CS-US association and activates multiple downstream structures that control the various expressions of fear. For example, active responses (like avoidance) and reactive responses (like suppression or freezing) to fear can be dissociated with lesions of nuclei downstream from the LA (Killcross et al., 1997; Amorapanth et al., 2000). Also, recording from the LA in an aversive instrumental task, where an odor was paired with quinine, demonstrated that negative odors elicited activity in the LA even after the animal had learned to avoid the quinine (Schoenbaum et al., 1999). Taken together, these findings favor the conclusion that activity in the LA is related to retrieval or processing of a CS and not linked to suppression or any other specific expression of fear in general. Our study adds evidence that activity in the LA is required for the retrieval of the CS-US association even when subjects are continually trained for weeks and when the contingency between the CS and US is probabilistic.

\section{MAINTENANCE OF FEAR}

The finding that PENT infusions into the LA prolonged CSevoked lick suppression past the offset of the CS not only implicates the LA in fear-memory retrieval, but also in the postretrieval maintenance of fear. Taken together, this suggests that activation of the LA is necessary for a CS to evoke a fear-memory, which in turn, triggers expression of fear and that de-activation of the LA is required for the return to a baseline non-fearful state. It has been proposed that the ability to recover quickly from an initial fear reaction may be an important factor that contributes to psychological resilience (Charney, 2004; Yehuda et al., 2006). Conversely, the inability to recover from fear may be a risk factor for an anxiety disorder such as PTSD. Interestingly, recent evidence suggests that fear-reactivity and sustained fear recovery are dissociable traits (Bush et al., 2007). Our current results suggest that the LA is involved both in the retrieval of a fear memory and in the short-term recovery from the same memory. Nonetheless, different neural mechanisms may underlie these two aspects of fear.

\section{ACKNOWLEDGMENTS}

This work was funded by NIH grant 5 R01 MH38774. Jeffrey C. Erlich was funded by a Howard Hughes Medical Institute pre-doctoral fellowship. 


\section{REFERENCES}

Amorapanth, P., LeDoux, J. E., and Nader, K. (2000). Different lateral amygdala outputs mediate reactions and actions elicited by a fear-arousing stimulus. Nat. Neurosci. 3, 74-79.

Amorapanth, P., Nader, K., and LeDoux, J. E. (1999). Lesions of periaqueductal gray dissociate-conditioned freezing from conditioned suppression behavior in rats. Learn. Mem. 6, 491-499.

Belcheva, I., Belcheva, S., Petkov, V. V., and Petkov, V. D. (1994). Asymmetry in behavioral responses to cholecystokinin microinjected into rat nucleus accumbens and amygdala. Neuropharmacology 33, 995-1002.

Blair, H. T., Huynh, V. K., Vaz, V. T., Van, J., Patel, R. R., Hiteshi, A. K., Lee, J. E., and Tarpley, J. W. (2005). Unilateral storage of fear memories by the amygdala. J. Neurosci. 25, 4198-4205.

Blanchard, R. J., Yudko, E. B., Rodgers, R. J., and Blanchard, D. C. (1993). Defense system psychopharmacology: an ethological approach to the pharmacology of fear and anxiety. Behav. Brain Res. 58, 155-165.

Bradwejn, J., Koszycki, D., and Meterissian, G. (1990). Cholecystokinin-tetrapeptide induces panic attacks in patients with panic disorder. Can. J. Psychiatry 35, 83-85.

Bush, D. E., Sotres-Bayon, F., and LeDoux, J. E. (2007). Individual differences in fear: isolating fear reactivity and fear recovery phenotypes. J. Trauma. Stress 20, 413-422.

Charney, D. S. (2004). Discovering the neural basis of human social anxiety: a diagnostic and therapeutic imperative. Am. J. Psychiatry 161, $1-2$.

Chhatwal, J. P., Gutman, A. R., Maguschak, K. A., Bowser, M. E., Yang, Y., Davis, M., and Ressler, K. J. (2009). Functional interactions between endocannabinoid and CCK neurotransmitter systems may be critical for extinction learning. Neuropsychopharmacology 34, 509-521.

Chu, T. F., and Lin, M. T. (1996). Picrotoxin induces both hypertension and dopamine release in the rat amygdala. Neurosci. Lett. 218, 169-172.

Chung, L., and Moore, S. D. (2009). Cholecystokinin excites interneurons in rat basolateral amygdala. J. Neurophysiol. 102, 272-284.

Davis, M., Myers, K. M., Chhatwal, J., and Ressler, K. J. (2006).
Pharmacological treatments that facilitate extinction of fear: relevance to psychotherapy. NeuroRx 3 , 82-96.

Dębiec, J., Bush, D. E., and Ledoux, J. E. (2011). Noradrenergic enhancement of reconsolidation in the amygdala impairs extinction of conditioned fear in rats-a possible mechanism for the persistence of traumatic memories in PTSD. Depress. Anxiety 28, 186-193.

Delgado, M. R., Nearing, K. I., Ledoux, J. E., and Phelps, E. A. (2008). Neural circuitry underlying the regulation of conditioned fear and its relation to extinction. Neuron 59, 829-838.

Dunsmoor, J. E., Bandettini, P. A., and Knight, D. C. (2008). Neural correlates of unconditioned response diminution during Pavlovian conditioning. Neuroimage 40, 811-817.

Edeline, J. M., Hars, B., Hennevin, E., and Cotillon, N. (2002). Muscimol diffusion after intracerebral microinjections: a reevaluation based on electrophysiological and autoradiographic quantifications. Neurobiol. Learn. Mem. 78, 100-124.

Ehrlich, I., Humeau, Y., Grenier, F., Ciocchi, S., Herry, C., and Lüthi, A. (2009). Amygdala inhibitory circuits and the control of fear memory. Neuron 62, 757-771.

Escobar, M., Arcediano, F., and Miller, R. R. (2002). Latent inhibition and contextual associations. J. Exp. Psychol. Anim. Behav. Process. 28, 123-136.

Foa, E. B., and Meadows, E. A. (1997). Psychosocial treatments for posttraumatic stress disorder: a critical review. Annu. Rev. Psychol. 48, 449-480.

Frankland, P. W., Josselyn, S. A., Bradwejn, J., Vaccarino, F. J., and Yeomans, J. S. (1997). Activation of amygdala cholecystokininB receptors potentiates the acoustic startle response in the rat. J. Neurosci. 17, 1838-1847.

Gean, P. W., and Shinnick-Gallagher, P. (1987). Picrotoxin induced epileptiform activity in amygdaloid neurons. Neurosci. Lett. 73, 149-154.

Geraci, M., Anderson, T. S., SlateCothren, S., Post, R. M., and McCann, U. D. (2002). Pentagastrin-induced sleep panic attacks: panic in the absence of elevated baseline arousal. Biol. Psychiatry 52, 1183-1189.

Jasnow, A. M., Ressler, K. J., Hammack, S. E., Chhatwal, J. P., and Rainnie, D. G. (2009). Distinct subtypes of cholecystokinin (CCK)-containing interneurons of the basolateral amygdala identified using a CCK promoter-specific lentivirus. J. Neurophysiol. 101, 1494-1506.

Johansen, J. P., Cain, C. K., Ostroff, L. E., and LeDoux, J. E. (2011). Molecular mechanisms of fear learning and memory. Cell 147, 509-524.

Killcross, S., Robbins, T. W., and Everitt, B. J. (1997). Different types of fear-conditioned behaviour mediated by separate nuclei within amygdala. Nature 388 , 377-380.

LaBar, K. S., Gatenby, J. C., Gore, J. C., LeDoux, J. E., and Phelps, E. A. (1998). Human amygdala activation during conditioned fear acquisition and extinction: a mixed-trial fMRI study. Neuron 20 , 937-945.

Lamprecht, R., and LeDoux, J. (2004). Structural plasticity and memory. Nat. Rev. Neurosci. 5, 45-54.

Maren, S. (2001). Neurobiology of Pavlovian fear conditioning. Annu. Rev. Neurosci. 24, 897-931.

Maren, S., and Quirk, G. J. (2004). Neuronal signalling of fear memory. Nat. Rev. Neurosci. 5, 844-852.

Martin, J. H. (1991). Autoradiographic estimation of the extent of reversible inactivation produced by microinjection of lidocaine and muscimol in the rat. Neurosci. Lett. 127, 160-164.

McGuire, J., Herman, J. P., Horn, P. S., Sallee, F. R., and Sah, R. (2010). Enhanced fear recall and emotional arousal in rats recovering from chronic variable stress. Physiol. Behav. 101, 474-482.

Meis, S., Munsch, T., Sosulina, L., and Pape, H. C. (2007). Postsynaptic mechanisms underlying responsiveness of amygdaloid neurons to cholecystokinin are mediated by a transient receptor potential-like current. Mol. Cell. Neurosci. 35, 356-367.

Msetfi, R. M., Murphy, R. A., Simpson, J., and Kornbrot, D. E. (2005). Depressive realism and outcome density bias in contingency judgments: the effect of the context and intertrial interval. J. Exp. Psychol. Gen. 134, 10-22.

Nader, K., Schafe, G. E., and Ledoux, J. E. (2000). Fear memories require protein synthesis in the amygdala for reconsolidation after retrieval. Nature 406, 722-726.

Pape, H. C., and Pare, D. (2010). Plastic synaptic networks of the amygdala for the acquisition, expression, and extinction of conditioned fear. Physiol. Rev. 90, 419-463.

Pare, D., Quirk, G. J., and Ledoux, J. E. (2004). New vistas on amygdala networks in conditioned fear. J. Neurophysiol. 92, 1-9.

Paxinos, G., and Watson, C. (2004). The Rat Brain in Stereotaxic Coordinates. New York, NY: Elsevier.

Phelps, E. A., Delgado, M. R., Nearing, K. I., and LeDoux, J. E. (2004). Extinction learning in humans: role of the amygdala and vmPFC. Neuron 43, 897-905.

Poole, K., Hood, K., Davis, B. D., Monypenny, I. J., Sweetland, H., Webster, D. J., Lyons, K., and Mansel, R. E. (1999). Psychological distress associated with waiting for results of diagnostic investigations for breast disease. Breast 8 , 334-338.

Quirk, G. J., Martinez, K. G., and Nazario Rodríguez, L. L. (2007). Translating findings from basic fear research to clinical psychiatry in Puerto Rico. P. R. Health Sci. J. 26, 321-328.

Repa, J. C., Muller, J., Apergis, J., Desrochers, T. M., Zhou, Y., and LeDoux, J. E. (2001). Two different lateral amygdala cell populations contribute to the initiation and storage of memory. Nat. Neurosci. 4, 724-31.

Ressler, K. J., Rothbaum, B. O., Tannenbaum, L., Anderson, P., Graap, K., Zimand, E., Hodges, L., and Davis, M. (2004). Cognitive enhancers as adjuncts to psychotherapy: use of D-cycloserine in phobic individuals to facilitate extinction of fear. Arch. Gen. Psychiatry 61, 1136-1144.

Rodrigues, S. M., Schafe, G. E., and LeDoux, J. E. (2004). Molecular mechanisms underlying emotional learning and memory in the lateral amygdala. Neuron 44, 75-91.

Rotzinger, S., and Vaccarino, F. J. (2003). Cholecystokinin receptor subtypes: role in the modulation of anxiety-related and reward-related behaviours in animal models. J. Psychiatry Neurosci. 28, 171-181.

Sanders, S. K., and Shekhar, A. (1995). Regulation of anxiety by GABAA receptors in the rat amygdala. Pharmacol. Biochem. Behav. 52, 701-706.

Schafe, G. E., Doyere, V., and LeDoux, J. E. (2005). Tracking the fear engram: the lateral amygdala is an essential locus of fear memory storage. J. Neurosci. 25, 10010-10014.

Schoenbaum, G., Chiba, A. A., and Gallagher, M. (1999). Neural encoding in orbitofrontal cortex and basolateral amygdala during olfactory discrimination learning. J. Neurosci. 19, 1876-1884.

Singh, L., Lewis, A. S., Field, M. J., Hughes, J., and Woodruff, G. N. 
(1991). Evidence for an involvement of the brain cholecystokinin B receptor in anxiety. Proc. Natl. Acad. Sci. U.S.A. 88, 1130-1133.

Thompson, T., and Hepburn, J. (2003). Causal uncertainty, claimed and behavioural self-handicapping. $\mathrm{Br}$. J. Educ. Psychol. 73, 247-266.

Tsetsenis, T., Ma, X. H., Lo Iacono, L., Beck, S. G., and Gross, C. (2007). Suppression of conditioning to ambiguous cues by pharmacogenetic inhibition of the dentate gyrus. Nat. Neurosci. 10, 896-902.

Wagner, A. R., Siegel, L. S., and Fein, G. G. (1967). Extinction of conditioned fear as a function of percentage of reinforcement.
J. Comp. Physiol. Psych. 63, Yehuda, R., Flory, J. D., Southwick, $160-167$.

Wilensky, A. E., Schafe, G. E., and LeDoux, J. E. (2000). The amygdala modulates memory consolidation of fear-motivated inhibitory avoidance learning but not classical fear conditioning. J. Neurosci. 20, 7059-7066.

Wilensky, A. E., Schafe, G. E., Kristensen, M. P., and LeDoux, J. E. (2006). Rethinking the fear circuit: the central nucleus of the amygdala is required for the acquisition, consolidation, and expression of Pavlovian fear conditioning. J. Neurosci. 26, 12387-12396.
S., and Charney, D. S. (2006). Developing an agenda for translational studies of resilience and vulnerability following trauma exposure. Ann. N.Y. Acad. Sci. 1071, 379-396.

Yu, A. J., and Dayan, P. (2005). Uncertainty, neuromodulation, and attention. Neuron 46, 681-692.

Conflict of Interest Statement: The authors declare that the research was conducted in the absence of any commercial or financial relationships that could be construed as a potential conflict of interest.
Received: 17 January 2012; accepted: 25 March 2012; published online: 10 April 2012.

Citation: Erlich JC, Bush DEA and LeDoux JE (2012) The role of the lateral amygdala in the retrieval and maintenance of fear-memories formed by repeated probabilistic reinforcement. Front. Behav. Neurosci. 6:16. doi: 10.3389/fnbeh.2012.00016 Copyright (C) 2012 Erlich, Bush and LeDoux. This is an open-access article distributed under the terms of the Creative Commons Attribution Non Commercial License, which permits noncommercial use, distribution, and reproduction in other forums, provided the original authors and source are credited. 